\title{
HIV - IMPLICATIONS FOR EXERCISE IN TREATMENT AND REHABILITATION
}

\begin{abstract}
Exercise is an integral part of many forms of rehabilitation following muscle injury or surgery. It is usual to advise patients with a viral infection to avoid exercise because of the risk of developing myocarditis. Should HIV+ patients should be encouraged to undertake exercise as part of rehabilitation and should they further be advised to participate in regular exercise? There is sufficient evidence to support the benefits of regular

Mars M, MBChB, MD'

1 Professor and Head of Department of TeleHealth, Nelson R Mandela School of Medicine, University of Natal. exercise in the HIV+ patient. They will experience a training effect dependent on the normal parameters of frequency, intensity, duration, and mode of exercise. The disease does place potential limitations to exercise, as the HI virus directly affects pulmonary, cardiac, skeletal muscle and endocrine function. The effects of these changes may be exacerbated by secondary infection and other pathological changes may be induced by treatment. The advent of highly active antiretroviral therapy has brought with it a range of metabolic changes that may also influence exercise participation. The limitations to exercise imposed by HIV infection and its treatment are reviewed.
\end{abstract}

\section{KEY WORDS: HIV, EXERCISE, LUNG FUNCTION, CARDIAC FUNCTION, SKELETAL MUSCLE, METABOLIC DISTURBANCE.}

It is currently estimated that there are over 50 million people in the world infected with the human immune deficiency virus (HIV). This constitutes about $0.8 \%$ of the world's population. Two thirds of the cases are in subSaharan Africa and about 10,000 people die each day of AIDS and its complications on this continent. Botswana has the dubious distinction of having the highest percentage of its population infected. South Africa has the most HIV positive people, approximately 4.5 million, with over a 1000 people dying daily of AIDS. Based on antenatal clinic attendance data, KwaZulu Natal is hardest hit in South Africa, with about a third of its population infected. It is sobering to note that in its 2002 update, the United Nations Population Division still predicts that the population of Africa will increase two and half fold by 2050 , and that the population of South Africa will decrease by $8 \%$.

The disease does not appear to be coming to a natural end. It is forecast that the epicentre of the disease will move from southern Africa to West Africa and then to India and that it will only peak in 40 to 60 years time.

As the HIV/AIDS pandemic continues, the pattern of the disease is changing. In the developed world, the advent of highly active antiretroviral therapy (HAART) has improved CD4 counts and reduced viral loads. As a result there is a reduction in opportunistic infection and the disease is being converted into a chronic illness. This partial success in the management if HIV/AIDS is not without cost, as the incidence of treatment associated or induced pathology, like lipodystrophy, increases. There are now reports of increasing ischaemic heart disease, stroke, glucose intolerance, diabetes and lactic acidosis in those on HAART.

In much of the developing world, where HAART is not freely available, the disease profile remains unchanged, with opportunistic infection and muscle wasting the features of the disease.

Knowingly or unknowingly, physiotherapists are treating $\mathrm{HIV}^{+}$patients daily, for conditions ranging from chest infections to muscle pain. It is stated that $76 \%$ of $\mathrm{HIV}^{+}$positive people in South Africa did not know that they are infected and of these, $63 \%$ did not know that they were at risk (Shisana 2003). The aim of this paper is to raise awareness and understanding of HIV/AIDS by reviewing the disease process, the principles of treatment, the effects of the disease on cardiopulmonary and skeletal muscle function and the effect of treatment on the body. The possible use of exercise as a treatment or rehabilitation modality will be discussed.

Data were acquired by searching the Medline and AIDSlit databases using the exploded keywords, HIV, AIDS, exercise and exertion. Using the Boolean command OR, HIV and AIDS were combined and exercise and exertion were combined. The two new subsets were then combined using the Boolean command AND to derive a search of HIV/AIDS AND Exercise/Exertion. Further searches were conducted of HIV/AIDS AND Cardiac function/ cardiac function testing, HIV/AIDS AND skeletal muscle, HIV/AIDS AND pulmonary function/pulmonary function testing, HIV/AIDS AND anabolic steroids, and HIV/AIDS AND Metabolism. This yielded 2252 papers. All papers in English on HIV/AIDS and exercise were acquired and reviewed and additional papers referenced in these papers were reviewed. All the abstracts of the other searches were read and the full papers of those

\section{CORRESPONDENCE TO:}

Prof Maurice Mars

Dept of TeleHealth

Nelson R Mandela School of Medicine

University of Natal

Private Bag 7, Congella 4013

mars@ukzn.ac.za 
abstracts that appeared to be pertinent were acquired and reviewed.

\section{THE VIRUS AND INFECTION PROCES}

The genome of a virus is an element of nucleic acid, either DNA or RNA. Viruses require a living host cell in which to reproduce as they lack the synthetic material to make new viral particles or virions which leave the host cell and exist in an extracellular form. The HI virus is a member of the lenti group of retroviruses. It binds via a glycoprotein (gp120) to the cell membrane of $\mathrm{T}$ lymphocytes that express the CD4 receptor site (Alkhatib et al 1996). These are the $\mathrm{T}$ helper cells that play a central role in the induction of virtually every phase of the human immune response. The virus "deposits" in the T lymphocyte, its dual RNA chains, and various enzymes. These include reverse transcriptase, which is necessary for decoding the viral RNA and forming viral DNA and an integrase which inserts the proviral DNA formed in the host T lymphocyte into the nuclear DNA of the host cell. The viral DNA then codes for viral proteins that are cleaved into viral subunits by a viral protease. The new HI virus buds off from the host cell membrane and infects other CD4 cells. Apart from the activity of viral replication and release, the normal functions of the infected $\mathrm{CD}^{+}{ }^{+} \mathrm{T}$ helper lymphocytes are affected. The infected CD4 cell ultimately dies resulting in a reduction CD4 count and an increase in the ratio of CD8 cells (cytotoxic and suppressor cells) to CD4 cells. CD4 lymphocytes are involved in co-ordinating and activating immunity while CD8 cells suppress immunity. In addition CD4 counts may be reduced by infection of CD4 precursor cells, gp120 induced apoptosis, formation of syncytia between healthy and infected cells and the production of various suppressor agents (Edelman and Zolla-Pazner 1989, Fauci 1988, Laurence and Mayer 1984).

The HI virus also infects monocytes, the cells responsible for the presentation of antigens to the $\mathrm{T}$ cells. The HI virus enters monocytes largely through phagocytosis and not through gp120-CD4 binding, although some monocytes do express the CD4 receptor. Unlike the CD4 cells, the monocytes do not die after infection and act as a reservoir or "viral manufacturing plant". Monocyte function is affected, with defective chemotaxis, reduced ability to kill target cells such as parasites, and reduction in production of Interleukin-1 (Lawless et al 1995, Talle et al 1983).

The Natural Killer cell (NK), which plays an important role in immune surveillance against tumour cells and viruses in non-specific natural immunity, is also affected. While NK cell numbers are not greatly affected in AIDS, their cytotoxicity is significantly reduced early in the disease process (Rosenberg and Fauci 1990, Talle et al 1983).

After primary infection, the disease enters a latent phase during which its presence in the extracellular fluids is low and relatively few CD4 cells are infected. The disease is not however quiescent and continues in the lymph nodes, where the virus multiplies in macrophages, follicular dendritic cells and in up to $10 \%$ of the CD4 cells (Pantaleo et al 1993, Rutherford et al 1990). The patients are usually asymptomatic in this phase and they are relatively healthy. During this phase they can transmit the disease and their immune system is compromised. As the disease progresses patients may develop symptoms such as fatigue, intermittent fever, lymphadenopathy, weight loss and diarrhoea without major opportunistic infections or cancer. This is known as the AIDS related complex. Eventually most patients will be diagnosed with AIDS, either through developing an AIDS deficiency illness such as an opportunistic infection or malignancy, or their CD4 count falling to below 200 cells. $\mathrm{mm}^{-3}$ (Rosenberg and Fauci 1990).

Treatment can be directed at each of the steps in this process. Viral binding can be inhibited by flooding the circulation with proteins that mimic the binding sites on the T lymphocytes. These attach to and effectively block the binding sites on the virus, thereby protecting other cells from the virus. The reverse transcriptase process can be inhibited by nucleoside and non-nucleoside reverse transcriptase inhibitors. Nucleoside inhibitors involve administering fake nucleosides, adenosine, thymidine, cytosine or guanine with the result that transcription of the viral RNA produces a "false" viral DNA. An example of this is zidivodine, or AZT. Non nucleoside reverse transcriptase inhibitors like nevirapine, competitively block reverse transcriptase. The host cells ribonucleotide production can also be blocked by ribonucleotide reductase inhibitors. The protease inhibitors block the cleavage, packaging and release of the newly formed viral RNA and viral proteins.

Monitoring the course of the disease in $\mathrm{HIV}^{+}$patients is usually done by following changes in CD4 counts or more recently viral load. There has been much debate on whether exercise raises CD4 counts, stabilises them, or slows the rate of decline. To interpret the data one needs to know the normal response of T lymphocytes to exercise in both the uninfected and infected individual. In addition the variability of the CD4 count test must be taken into account when drawing conclusions based on CD4 counts.

Exercise induces both neutrophilia and lymphocytosis during exercise. After exercise the neutrophilia persists while lymphopaenia develops, with lymphocyte counts dropping to below pre-exercise values. The increase of the lymphocyte subsets differs during exercise with CD16 Natural Killer cells showing the greatest increase and CD4 cells undergoing a relatively small increase. Natural killer cell and lymphokine activated killer cell (LAK) activity is increased during and immediately after exercise of moderate intensity and duration (Pedersen et al 1998). In $\mathrm{HIV}^{+}$patients subjected to 1 hour of exercise at $75 \% \mathrm{VO}_{2} \max$ on a cycle ergometer, lymphocyte responses to exercise and recovery were similar to that of controls but the level of elevation of the lymphocyte subsets during exercise was decreased. Similarly, NK and LAK activity during and after activity was less than that of controls (Ullum et al 1994).

As the CD4 count is used as an indicator of the possible benefits of exercise in $\mathrm{HIV}^{+}$patients, the important observations on the variability of CD4 counts made by Raboud et al. need to be detailed (Raboud et al 1995). They emphasised the need to know the co-efficient of variation of the test in different labs. In their own lab, repeat tests on the same 
sample had a coefficient of variation of $13.7 \%$ with the median difference between 2 tests of 16 cells. $\mathrm{mm}^{-3}$. While this may appear to be an acceptable variation, the maximum difference was 105 cells. $\mathrm{mm}^{-3}$. They concluded that in their lab, a change of more than $27 \%$ would be required in the short term to be confident that a meaningful change has occurred.

In summary, the CD4 cells are infected and lose their function of signalling other cells in the immune system to mount adequate cellular and humoral immune responses. Natural immunity is impaired because of the failure of monocytes and NK cells to provide immune surveillance against parasites, other pathogens and tumour cells and their inability to produce normal concentrations of cytokines, results in a breakdown of cell to cell signalling. The clinical course of the disease can be monitored by the falling CD4 count and rising plasma viral load.

\section{STAGING OF THE DISEASE}

The two most commonly cited classifications of the disease are the Walter Reed Staging and Centre for Disease Control (CDC) classification (Tables 1 and 2).

\section{EXERCISE AND HIV}

\section{Oxygen Uptake, Delivery and Consumption}

Patients with HIV infection who do not have full blown AIDS or pulmonary infection have reduced work capacity, lower aerobic threshold, and poorer aerobic capacity than age matched controls (Johnson et al 1990, Keyser et al 2000, Roge et al 2002, Smith et al 2001). Oxygen consumption during exercise is dependent on its uptake from the lungs, delivery by the heart and blood and its utilisation by skeletal muscle. These will be addressed separately.

\section{PULMONARY FUNCTION \\ The Effect of the Disease on the Lungs}

The lungs are a common site of secondary or opportunistic infection in HIV/AIDS, but the HI virus also has a direct effect on the lung physiology. Reduction in diffusion capacity without overt lung disease is a common pulmonary feature of HIV infection (Kvale et al 1993, McCabe et al 1997). This worsens with time and a diffusion capacity of $<80 \%$ predicted is associated with a more rapid progression of the disease to AIDS (Nieman et al 1993). In addition, most lung function tests are abnormal in the $\mathrm{HIV}^{+}$population.

Decreased diffusion capacity is associated with reduced pulmonary capillary blood volume, well-preserved total lung capacity and no evidence of interstitial fibrosis. There is evidence of early emphysema and focal air trapping, the severity of which correlates with diffusion capacity (Diaz et al 1999). Associated with this are significant reductions in mean FEV1 and forced mid-expiratory flow (Gelman et al 2000). Bronchial dilatation may also be present and this has been linked to increased neutrophil concentrations found on bronchoalveolar lavage (King et al 1997). The concentration of the antioxidant glutathione found in the respiratory epithelial lining fluid is reduced in $\mathrm{HIV}^{+}$subjects and the concentration falls with time (Pacht et al 1997).

\section{Exercise and Lung Function}

Johnson et al. compared pulmonary function at rest and during exercise in $32 \mathrm{HIV}^{+}$soldiers, without AIDS and

Table 1: Walter Reed Classification.

\begin{tabular}{|l|l|}
\hline \multicolumn{1}{|c|}{ Walter Reed Classification } \\
\hline W R 1 & CD4 count $\geq 400 \cdot \mathrm{mm}^{-3}$, no signs or symptoms, \\
\hline W R 2 & CD4 count $\geq 400 \cdot \mathrm{mm}^{-3}$, lymphadenopathy present, \\
\hline W R 3 & CD4 count $<400 \cdot \mathrm{mm}^{-3}$, normal delayed hypersensitivity, \\
\hline W R 4 & CD4 count $<400 \cdot \mathrm{mm}^{-3}$, partial cutaneous anergy \\
\hline W R 5 & CD4 count $<400 \cdot \mathrm{mm}^{-3}$, complete cutaneous anergy or oral thrush present \\
\hline W R 6 & CD4 count $<400 \cdot \mathrm{mm}^{-3}$, opportunistic infection present. \\
\hline
\end{tabular}

Table 2: Centre for Disease Control coding for AIDS.

\begin{tabular}{|l|l|}
\hline \multicolumn{2}{|c|}{ Centre for Disease Control } \\
\hline A & $\begin{array}{l}\text { Asymptomatic. Patient able to transmit the disease and immune function } \\
\text { compromised. }\end{array}$ \\
\hline B & $\begin{array}{l}\text { Early symptomatic pre-A IDS. Fever and or diarrhoea persisting more } \\
\text { than 1 month, involuntary weight loss and or a diagnosis of an infectious } \\
\text { disease associated with HIV-1 and indicative of a defect in cell mediated } \\
\text { immunity }\end{array}$ \\
\hline C & $\begin{array}{l}\text { AIDS. CD4 count <200 cells. } \text { mm }^{-3} \text { and or the presence of a major } \\
\text { complication such as an opportunistic infection or malignancy. }\end{array}$ \\
\hline
\end{tabular}

with no overt or pre-existing pulmonary or cardiac disease, with an age matched control group. The $\mathrm{HIV}^{+}$subjects complained of dyspnoea on exertion or difficulty with mandatory exercise. While pulmonary function tests were normal, patients exercised to a significantly lower workload and had a significantly lower anaerobic threshold. Maximal oxygen consumption $\left(\mathrm{VO}_{2} \max \right)$ and minute ventilatory volume were nonsignificantly lower, and maximal heart rates were similar. The slope of the heart rate vs $\mathrm{VO}_{2}$ relationship was increased indicating that the heart rate of the patients was greater than that of the controls at any given oxygen consumption. They concluded that some seropositive patients have impairment in maximal exercise capability and that there was no evidence that this was due to a ventilatory limitation. They felt that the findings were consistent with a problem of oxygen delivery to the muscles secondary to cardiac problems. It should be noted however that only one subject had a mild reduction of single breath, oxygen diffusion capacity (Johnson et al 1990).

Pulmonary function is affected by repeated bouts of pneumonia which reduce pulmonary diffusing capacity, 
ventilatory volume, oxygen consumption and oxygen pulse during exercise. The initial effect of this is haemoglobin desaturation during vigorous exercise, which develops into desaturation with light exercise. Exercise induced desaturation is used as a simple test to diagnose Pneumocystis carinii pneumonia (PCP) in $\mathrm{HIV}^{+}$patients (Chouaid et al 1995).

The effects of pneumonia on pulmonary function in HIV/AIDS have been examined by Pothoff et al, who performed pulmonary function and cardiopulmonary exercise tests on three groups of $\mathrm{HIV}^{+}$and AIDS patients. Subjects in group1 had not had pneumonia, those in group 2 had just recovered from PCP pneumonia, and group 3 had a current chest infection. They were compared with an HIVcontrol group, free of pulmonary infection. All $\mathrm{HIV}^{+}$groups had reduced oxygen diffusing capacity and reduced exercise capacity compared to controls. Lung function assessed by spirometry was significantly reduced in group 3 and oxygen diffusion capacity was significantly reduced between groups. Heart rate at any given oxygen consumption increased from group 1 to 3 . Similarly oxygen consumption at anabolic threshold, peak $\mathrm{VO}_{2}$ and oxygen pulse decreased from group 1 to 3 . Alveolar arterial oxygen difference was also significantly greater during exercise in group 3. They concluded that HIV infection is associated with impairment of diffusing capacity and exercise capacity and questioned whether the problem was in oxygen delivery or muscle utilisation (Pothoff et al 1994).

\section{The Effect of HIV on Heart.}

Resting heart rate is elevated in HIV infection and this is attributed to an increase in resting energy expenditure due to high viral load, HAART, night sweats, fever and secondary infection (Shevitz and Knox 2001a). Cardiac pathology is evident early in the disease. Cardiac abnormalities have been reported in $25-73 \%$ of $\mathrm{HIV}^{+}$adults, and are found at autopsy in two thirds of AIDS patients (Steinherz et al 1986). Left ventricular dysfunction and ECG abnormalities are common sequelae (Barbaro et al 1996a, Cardoso et al 1998, Hernandez et al 2001, Herst et al
1991, Milei et al 1998) and the right side of the heart may also be involved (Casalino et al 1996). Cardiac causes of mortality, however, are estimated at only $1-6 \%$ (Mehta et al 2002). Pericardial effusion, pericarditis, myocarditis, cardiomyopathy, endocarditis, pulmonary hypertension and cardiac lymphomas are among the many known cardiac manifestations of HIV infection (Duong et al 1997, Milei et al 1998).

The virus appears to have a direct effect on the myocardium and approximately $50 \%$ of AIDS patients have a lymphocytic myocarditis at autopsy for which no specific aetiological factor can be found, (Milei et al 1998) and approximately a quarter of these patients will have had ventricular arrhythmias (Barbaro et al 1996b).

\section{Effect of Treatment on the Heart}

Changes in ventricular wall thickness appear to be dependent on the stage of the disease and treatment. Protease inhibitors have been linked to increases in posterior wall thickness, septum thickness, left atrial dimension and LV mass and this appears to be related to the duration of treatment (Meng et al 2002). Zidovudine (AZT) has been linked to left ventricular hypertrophy, increased left ventricular mass and increases the risk of cardiomyopathy in children (Domanski et al 1995, Lipshultz et al 1992).

In aids wasting syndrome (AWS) there is a significant reduction in left ventricular mass when corrected for body surface area. This is associated with left ventricular dysfunction (Samaan et al 1995).

Since the advent of HAART, lipid and metabolic disorders have increased in the $\mathrm{HIV}^{+}$population. Protease inhibitors have been suggested as the cause of atherosclerosis and coronary artery disease in HIV (Boccara et al 2002, Mehta et al 2002). Coronary artery disease is also considered to be increasing and silent myocardial ischaemia has been documented in $11 \%$ of subjects with no cardiac symptoms or history, with a significant correlation between silent infarct and obesity, waistto-hip ratio, central fat accumulation, and glucose and cholesterol concentrations (Duong et al 2002).

\section{The Effect of Exercise on the Heart}

Heart rate is raised at rest and during submaximal graded exercise tests but maximum heart rate does not appear to be affected (Johnson et al 1990, Johnson et al 1991). Aerobic training in $\mathrm{HIV}^{+}$ individuals evokes the same responses of reduced heart rate at a given submaximal workload and reduced resting and recovery heart rate seen in the uninfected (Keyes et al 1989, MacArthur et al 1993, Rigsby et al 1992). There is limited information on direct studies of the heart during or immediately after exercise.

In a study of 21 patients with AIDS and no history of cardiac symptoms, radionucleotide angiography was performed at rest and after exercise and compared with 12 age matched subjects who also had no history of cardiac disease. Eleven patients had abnormal ECG's, a third had right ventricular dilatation, and wall motion abnormalities were seen in 9 patients, with the right ventricle affected in 8 of the 9 patients. No dilatation or wall motion abnormalities were seen in the control group. Importantly, the mean left ventricular ejection fraction at rest and after exercise was not different between groups. In 7 of the 15 patients, ejection fraction was unchanged or reduced after exercise (Herst et al 1991).

Nine $\mathrm{HIV}^{+}$subjects with dyspnoea on exertion, $\mathrm{a} \mathrm{VO}_{2}$ max of less than $80 \%$ of predicted, a low ventilatory threshold, no opportunistic infection and no known pre-existing cardiac or pulmonary disease underwent right-sided cardiac catheterisation. They were compared against historical controls. Three of the 9 patients had abnormal ECG's, and 2 were normal in every respect in terms of non-invasive exercise testing. Catheterisation data revealed that right atrial and pulmonary capillary wedge pressures were higher in the patient group during exercise and pulmonary artery pressure was higher in the patient group at rest but not during exercise. Cardiac output data during rest and exercise were not different between groups. Mixed venous saturation was significantly lower in the patient group at rest and the arterio-venous $\mathrm{O}_{2}$ content difference was higher. The patients exercised to the same submaximal 
workload as the controls and had a similar $\mathrm{VO}_{2}$ and cardiac index response. This was achieved at higher filling pressures for both the right and left ventricles, a feature indicative of cardiac disease (Johnson et al 1991).

\section{Anaemia}

Anaemia is a feature of HIV/Aids and will affect aerobic exercise performance by reducing oxygen carriage and hence oxygen delivery to working muscle. Anaemia alone may account for the reduction in $\mathrm{VO}_{2}$ max noted in some studies (Pothoff et al 1994, Stringer 2000).

\section{Skeletal Muscle}

Muscle is severely affected by AIDS. Illness with decreased physical activity causes deconditioning and muscle atrophy. In addition there are the problems of AIDS wasting syndrome with loss of muscle mass, HIV polymyositis, Zidovudine therapy induced mitochondrial myopathy and myositis (MacArthur et al 1993, Sheik et al 1999, Stringer 2000). At autopsy, $70 \%$ of AIDS victims show microscopic abnormalities of muscles (Wrzolek et al 1990).

HIV can cause a skeletal muscle myopathy that is associated with progressive proximal weakness, elevated creatine phosphokinase, myofibrillar damage, fibre necrosis, inflammatory infiltrates and lipid droplet accumulation (Bailey et al 1987, Sheik et al 1999, Simpson and Bender 1988). Treatment induced myopathies also occur. Zidovudine, causes a mitochondrial myopathy with ragged-red fibres, fibre necrosis, lipid drop accumulation, increased size and number of mitochondria, disorganisation of cristae and mitochondrial DNA depletion (Sheik et al 1999). This occurs in skeletal muscle but not in cardiac muscle. Associated with this is an increase in plasma lactate concentration (Chariot et al 1999) that has been attributed to nucleoside reverse transcriptase inhibitors (NRTI), inhibiting mitochondrial DNA polymerase $\gamma$. This inhibits replication of mtDNA that encodes subunits of the enzymes of the respiratory chain. As a result there is reduced oxidative phosphorylation, necessitating increased conversion of pyruvate to lactate to produce ATP for muscle contaction (Aggarwal et al 1996). The myopathy responds well to stopping Zidovudine.

\section{Muscle Loss and Aids Wasting Syndrome}

Maintenance of adequate nutrition can be a problem in HIV infection. Resting energy expenditure is increased by about $10 \%$ in weight stable $\mathrm{HIV}^{+}$men without active opportunistic disease and may be further raised by illness and or treatment (Heijligenberg et al 1997). Nutritional status is affected by reduced oral intake because of associated nausea, anorexia and oral infection or by reduced absorption because of diarrhoea or malabsorption (Shevitz and Knox 2001b). In many people the deficit in daily energy intake exceeds the energy conserved by reduced physical activity and weight is lost. This should be taken into account when considering adding exercise, with its additional energy demands, to the treatment regimen.

In the early stage of HIV infection, there are minimal changes in body weight. There are however changes in body composition, with body cell mass decreasing and total body water increasing. Subsequent opportunistic infection results in anorexia, negative nitrogen balance and wasting. Muscle mass is severely affected in advanced AIDS. As muscle is the primary reserve of amino acids for gluconeogenesis and protein synthesis, the loss of muscle mass results not only in loss of strength but also loss of substrate (Sattler et al 1999).

The acquired immunodeficiency syndrome wasting syndrome (AWS) is characterised by the loss of lean body mass out of proportion to weight (Kotler et al 1989, Kotler et al 1998). In men it is defined as $10 \%$ weight loss at any time, $5 \%$ weight loss over 6 months or a BMI < 20 kg.m ${ }^{-2}$ (Roubenoff and Wilson 2001). AWS is associated with low testosterone concentrations and hypogonadism has been reported in up to $50 \%$ of men with AIDS (Dobs et al 1988). Approximately $60 \%$ of women with AWS are also reported to have an androgen deficiency (Grinspoon and Mulligan 2003). Serum androgen concentrations have been shown to correlate with lean body mass in males and females (Grinspoon et al 1996) and loss of lean body mass is associated with decreased survival. Despite the loss of muscle mass, patients with AWS retain the ability to respond to exercise with protein synthesis and exercise induced protein synthesis in AWS may be greater than in $\mathrm{HIV}^{+}$patients without AWS (Roubenoff et al 2001). Various methods of increasing muscle mass, reducing weight loss and improving strength are resistance training and treatment with androgenic agents that include anabolic steroids, (Bhasin et al 2000, Sattler et al 2002, Strawford et al 1999) recombinant human growth hormone (Corcoran 1998, Grinspoon and Mulligan 2003) and appetite stimulants (Steinhart 2001).

Obesity has been reported in one longitudinal study on patients on HAART, with $5 \%$ of men and $20 \%$ of women having a Body Mass Index $>30 \mathrm{~kg} / \mathrm{m}^{2}$ ) (Shevitz and Knox 2001b). The effect of HAART on catastrophic weight loss and AWS is less clear, with some contending that AWS is the AIDS defining condition in $>20 \%$ of patients and that the incidence of wasting does not appear to be influenced by HAART (Roubenoff and Wilson 2001, Shevitz and Knox 2001b). A recent 8 month longitudinal study reports AWS as low as $2 \%$, with loss of lean body mass in patients on HAART being related to the actions of catabolic cytokines and not inadequate dietary intake or hypogonadism (Roubenoff et al 2002a).

Exercise can play a role in the treatment of both those who have wasting and the obese. Strength training associated with adequate nutritional intake is associated with increased lean muscle mass (Fairfield et al 2001) and combined aerobic and strength training can reduce trunk fat (Roubenoff et al 1999b). Exercise adds to the daily energy expenditure and this needs to be taken into account.

\section{Lipid Disorders and Lipodystrophy}

Data from the pre-HAART era show depressed total cholesterol and low density lipoprotein concentrations early in the disease with moderately increased serum triglyceride and reduced cholesterol concentrations features of advanced HIV disease (Grunfeld et al 1992). The introduction of HAART has improved life expectancy but has also seen a range of changes in body fat in 
$20 \%-80 \%$ of people on HAART (Sattler 2003). Lipodystrophy is associated with atrophy of peripheral fat in the legs, arms and face and an increase in the abdominal fat, both subcutaneous and visceral, and local fat aggregations. Associated with lipodystrophy are raised serum triglyceride and cholesterol concentrations and peripheral insulin resistance with hyperinsulinaemia, hyperglycaemia and diabetes mellitus.

The pathogenesis is as yet unknown and is probably multifactorial, with HIV infection, antiretroviral drugs and host genetic factors implicated. The possible causal relationship of protease inhibitors and lipodystrophy is not confirmed because patients not on these drugs may also develop lipodystrophy, but fat wasting is faster in those on protease inhibitors (Sattler 2003). Cross sectional studies have also linked non reverse transcriptase inhibitors to lipodystrophy, on the basis of possibly causing mutations in the mtDNA gene and impairing oxidative phosphorylation (Christeff et al 2002).

Endocrine changes have also been suggested as a factor in lipodystrophy. Serum cortisol concentrations are raised in $\mathrm{HIV}^{+}$individuals irrespective of treatment. Dehydroepiandrosterone (DHEA) concentration is normal early in the disease but then falls as the disease progresses to AIDS. The effect of this is to raise the cortisol:DHEA ratio. With HAART, those who get lipodystrophy have a marked reduction in DHEA, while HAART elevates DHEA and restores the cortisol:DHEA ratio in those who do not have lipodystrophy (Christeff et al 1999, Christeff et al 2000). In women, significantly increased testosterone concentrations and an increased FSH:LH ratio is found in lipodystrophy (Hadigan et al 2000).

Lipodystrophy has also been shown to have both physical and psychological effects ranging from bodily discomfort to low self esteem and depression. It is also seen as a visible marker of HIV disease (Power et al 2003).

Until suitable pharmacological interventions are available it is suggested that the cornerstone of management for central fat accumulation should be diet and exercise (Borderi et al 2001, Sattler 2003). Aerobic exercise on its own,
(Thoni et al 2002) or in combination with a moderate fat, low glycaemic index, high fibre diet, (Roubenoff et al 2002 b) or with resistance training (Jones et al 2001) has led to improvements in total abdominal fat and blood lipid profiles. Progressive resistance exercise can also decrease truncal fat as measured by DEXA and CT with little effect on limb fat distribution (Roubenoff et al 1999b).

\section{Osteopaenia and Osteoporosis}

Bone metabolism is altered in HIV infection irrespective of the treatment. The prevalence of osteopaenia ( $\mathrm{t}$ score $<1-2.5 \mathrm{SD}$ ) is reported to be between $22 \%$ and $42 \%$ in patients on combination antiretroviral therapy (Carr et al 2001, Tebas et al 2000). Osteopaenia has been linked to raised lactate concentrations (Carr et al 2001). HAART has been shown to significantly reduce both total and regional bone mineral content when compared to those not on HAART and these effects increase with the duration of HAART (McDermott et al 2001). It is suggested that $\mathrm{HIV}^{+}$patients with osteopaenia or osteoporosis should be treated similarly to HIV seronegative patients with appropriate use of nutritional supplements (calcium and vitamin D) and exercise. Hormone replacement and antiresorptive therapies might also be indicated (Mondy and Tebas 2003). The potential role of exercise in the management of osteopaenia in the $\mathrm{HIV}^{+}$ is not yet clear as a 16 week programme of aerobic and resistance exercise did not alter bone mineral content in a group of $\mathrm{HIV}^{+}$men with lipodystrophy (Roubenoff et al 1999b).

\section{Psychological Factors}

Not surprisingly the HIV infected, undergo psychological stress and this may inhibit their enrolment in exercise programmes. Exercise is known to alter mood in the uninfected and improvements in mood, anxiety and depression are commonly reported in studies on exercise in patients with HIV (Birk et al 1996, Florijn 1992, LaPerriere et al 1991, LaPerriere et al 1994, Reussner et al 1992, Schlenzig et al 1989, Smith et al 1996, Smith et al 1998, Stringer et al 1998, Terry et al 1999) For a more detailed review of the field of psycho- neuroimmunology and its applicability in $\mathrm{HIV}^{+}$patients, the reader is referred to the work of LaPerriere and colleagues, in which they present their heuristic model of how exercise training might attenuate the immunosuppressive effects of psychological stress (LaPerriere et al 1994).

\section{Other Factors}

The potential benefits of exercise in the $\mathrm{HIV}^{+}$population appear to outweigh the risks. Participation in regular exercise is not widely practised in many countries and it is influenced by cultural and societal norms and practices. It is interesting to note that in the USA, approximately $40 \%$ to $60 \%$ of $\mathrm{HIV}^{+}$ individuals report using aerobic exercise or increasing their physical exercise as an alternative form of treatment, while only about $15 \%$ of the general population exercise on a regular basis (Roubenoff 2000). In many countries the poorer communities are most affected and adequate nutrition, suitable facilities, supervision and support for exercise may not be available or are unaffordable. Unfortunately the value of exercise has not been fully appreciated by all health professionals and some still advise their patients against exercise.

Patients too may avoid exercise as the disease makes them feel unwell. The associated diarrhoea, anorexia, nausea, secondary infection and depression are all factors that would support exercise avoidance.

\section{Cardiopulmonary Evaluation}

Should the $\mathrm{HIV}^{+}$patient undergo a cardiac evaluation before starting exercise? Approximately $50 \%$ of individuals who are asymptomatic of cardiac disease will have a demonstrable abnormality on ECG, echocardiogram or Doppler ultrasonography. In addition $10 \%$ of those on HAART who are asymptomatic of heart disease will have evidence of a silent myocardial infarct on stress ECG. Duong et al. have suggested that "exercise testing might be recommended for patients with HIV who have central fat accumulation and hypercholesterolaemia" (Duong et al 2002). On the basis of the link between HIV related myocarditis and ventricular ectopic beats, those with arrhythmias and those 
with known cardiac symptoms should also be assessed before embarking on an exercise programme.

Stringer suggests that cardiopulmonary exercise testing should be routinely performed on all $\mathrm{HIV}^{+}$ patients before starting an exercise programme. The proposed benefits being the unmasking of subtle cardiopulmonary pathology and guiding exercise prescription (Stringer 2000).

\section{Guidelines for Ex ercise}

The use of exercise in a viral infection seems anomalous when based on the principle of avoiding exercise in the presence of a viral infection because of the risk of developing a myocarditis. To date there are no data on the long term effects of exercise on the development or progression of HIV myocarditis. Certainly in the pre HAART era, the benefits of exercise appeared to outweigh the risks. With HAART, and longer survival and the emerging lipid disorders, the effect of exercise on HIV myocarditis needs further investigation.

While there is as yet no evidence to suggest that exercise might increase a patient's life-span, there is sufficient evidence to support the advice that $\mathrm{HIV}^{+}$patients should be encouraged to undertake regular exercise. They will experience a training effect dependent on the normal parameters of frequency, intensity, duration, and mode of exercise. It appears that the first bout of exercise will not detrimentally affect their immune status (Roubenoff et al 1999a). Exercise should be tailored to meet their individual requirements. These may vary from aerobic training to improve work capacity or reduce abdominal lipid accumulation, to resistance training to improve strength and maintain or gain weight. General exercise training should include mixed aerobic and resistance modes.

There is no paper that gives specific guidelines on constructing an exercise programme for these patients and it is suggested that general principles are followed. Aerobic exercise programmes should therefore consist of three to five sessions a week, of twenty minutes to an hour's duration, at an intensity of 50 $85 \%$ of maximum heart rate or $45-80 \%$ of $\mathrm{VO}_{2} \max$. The patient's symptoms, such as nausea, vomiting, diarrhoea, if present may dictate the intensity and or duration of each exercise bout. It is suggested that large muscle groups should be targeted in resistance exercise with 8 - 12 repetitions per exercise, increasing the resistance with time as the patient regains strength (Ciccolo et al 2004).

The addition of androgenic agents to resistance training appears to be an acceptable option in selected patients with AIDS wasting syndrome, or in those patients who have difficulty in complying with the training programme and who are losing weight. While regular exercise will impart psychological benefits, the benefit to their immune system is still controversial. Regular exercise is not associated with an increased risk of minor or opportunistic infection. The weight of evidence suggests that moderate exercise will not depress immunity, but may at best slow its insidious decline.

\section{REFERENCES}

Aggarwal A, al Talib K, Alabrash M 1996 Type B lactic acidosis in an AIDS patient treated with zidovudine. Maryland Medical Journal 45:929- 931

Alkhatib G, Combadiere C, Broder CC, Feng Y, Kennedy PE, Murphy PN, Berger EA 1996 CC CKr5: A RANTES, MIP-1alpha, MIP-1beta receptor as a fusion cofactor for macrophage-tropic HIV-1. Science 272: 1955-1958

Bailey RO, Turok DI, Jaufmann BP, Singh JK 1987 Myositis and acquired immunodeficiency syndrome. Human Pathology 18:749-751

Barbaro G, Barbarini G, Di Lorenzo G 1996a

Early impairment of systolic and diastolic function in asymptomatic HIV-positive patients: a multicenter echocardiographic and echo-Doppler study. The Gruppo Italiano Per lo Studio Cardiologico dei Pazienti Affetti da AIDS. AIDS Research and Human Retroviruses 12:1559-1563

Barbaro G, Di Lorenzo G, Grisorio B, Barbarini G 1996b Clinical meaning of ventricular ectopic beats in the diagnosis of HIV-related myocarditis: a retrospective analysis of Holter electrocardiographic recordings, echocardiographic parameters, histopathological and virologic findings. Cardiologia 41:1199-1207

Bhasin S, Storer TW, Javanbakht M, Berman N, Yarasheski KE, Phillips, J, Dike M, Sinha-Hikim I, Shen R, Hays RD, Beall G 2000 Testosterone replacement and resistance exercise in HIV-infected men with weight loss and low testosterone levels. Journal of the American Medical Association 283:763-770
Birk TJ, MacArthur RD, McGrady A, Khuder S 1996 Lack of effect of 12 weeks of massage therapy on immune function and quality of life in HIV-infected persons. International Conference on AIDS 11:270

Boccara F, Teiger E, Cohen A 2002 Stent implantation for acute left main coronary artery occlusion in an HIV-infected patient on protease inhibitors. Journal of Invasive Cardiology 14:343-346

Borderi M, Verucchi G, Tadolini M, Spinosa S, Fortunato L, Talo S, Chiodo F 2001 Metabolic complications of HIV-1 antiretroviral therapy: the lipodystrophy syndrome. New Microbiologica 24:303-315

Cardoso JS, Moura B, Martins L, MotaMiranda A, Rocha GF, Lecour H, Blanc P, Boussuges A, Souk-aloun J, Gauzere BA, Sainty JM 1998 Left ventricular dysfunction in human immunodeficiency virus (HIV)infected patients: Echocardiography on HIV patients admitted to the ICU. International Journal of Cardiology 63:37-45

Carr A, Miller J, Eisman JA, Cooper DA 2001 Osteopenia in HIV-infected men: association with asymptomatic lactic acidemia and lower weight pre-antiretroviral therapy. AIDS 15: 703-709

Casalino E, Laissy JP, Soyer P, Bouvet E, Vachon F 1996 Assessment of right ventricle function and pulmonary artery circulation by cine-MRI in patients with AIDS. Chest 110:1243-1247

Chariot P, Drogou I, Lacroix-Szmania I, Eliezer-Vanerot MC, Chazaud, B, Lombes A, Schaeffer A, Zafrani ES 1999 Zidovudineinduced mitochondrial disorder with massive liver steatosis, myopathy, lactic acidosis, and mitochondrial DNA depletion. Journal of Hepatology 30:156-160

Chouaid C, Housset B, Lebeau B 1995 Costanalysis of four diagnostic strategies for Pneumocystis carinii pneumonia in HIVinfected subjects. European Respiratory Journal 8:1554-1558

Christeff N, Melchior JC, de Truchis P, Perronne C, Gougeon ML 2002 Increased serum interferon alpha in HIV-1 associated lipodystrophy syndrome. European Journal of Clinical Investigation 32:43-50

Christeff N, Melchior JC, de Truchis P, Perronne C, Nunez EA, Gougeon, ML. 1999 Lipodystrophy defined by a clinical score in HIV-infected men on highly active antiretroviral therapy: correlation between dyslipidaemia and steroid hormone alterations. AIDS 13:2251-2260

Christeff N, Nunez EA, Gougeon ML 2000 Changes in cortisol/DHEA ratio in HIVinfected men are related to immunological and metabolic perturbations leading to malnutrition and lipodystrophy. Annals of the New York Academy of Sciences 917:962-970 Ciccolo JT, Jowers EM, Bartholomew JB 2004 The benefits of exercise training for quality of life in HIV/AIDS in the post-Haart era. Sports Medicine 34:487-499 
Corcoran C 1998 Approaches to the AIDS Wasting Syndrome. Positive Directions News 10:24-27

Diaz PT, King MA, Pacht ER, Wewers MD, Gadek JE, Neal D, Nagaraja, HN, Drake J, Clanton TL 1999 The pathophysiology of pulmonary diffusion impairment in human immunodeficiency virus infection. American Journal of Respiratory and Critical Care Medicine 160:272-277

Dobs AS, Dempsey MA, Ladenson PW, Polk BF 1988 Endocrine disorders in men infected with human immunodeficiency virus. American Journal of Medicine 84:611-616 Domanski MJ, Sloas MM, Follmann DA, Scalise PP, III, Tucker EE, Egan, D, Pizzo PA 1995 Effect of zidovudine and didanosine treatment on heart function in children infected with human immunodeficiency virus. Journal of Pediatrics 127:137- 146

Duong M, Cottin Y, Piroth L, Fargeot A, Lhuiller I, Bobillier M, Grappin M, Buisson M, Zeller M, Chavanet P, Wolf JE, Portier H 2002 Exercise stress testing for detection of silent myocardial ischemia in human immunodeficiency virus-infected patients receiving antiretroviral therapy. Clinical Infectious Diseases 34:523-528

Duong M, Dubois C, Buisson M, Eicher JC, Grappin M, Chavanet P, Portier H 1997 NonHodgkin's lymphoma of the heart in patients infected with human immunodeficiency virus. Clinical Cardiology 20:497 -502

Edelman AS, Zolla-Pazner S 1989 AIDS: a syndrome of immune dysregulation, and deficiency. FASEB Journal 3:22-30

Fairfield WP, Treat M, Rosenthal DI, Frontera W, Stanley T, Corcoran C, Costello M, Parlman K, Schoenfeld D, Klibanski A, Grinspoon S 2001 Effects of testosterone and exercise on muscle leanness in eugonadal men with AIDS wasting. Journal of Applied Physiology 90:2166-2171

Fauci AS 1988 The human immunodeficiency virus: infectivity and mechanisms of pathogenesis. Science 239:617-622

Florijn YC 1992 Physical activity as a therapeutic measure for HIV-infected persons. International Conference on AIDS 8:224

Gelman M, King MA, Neal DE, Pacht ER, Clanton TL, Diaz PT 2000 Focal air trapping in patients with HIV infection: CT evaluation and correlation with pulmonary function test results. Thorax 55:32-38

Grinspoon S, Corcoran C, Lee K, Burrows B, Hubbard J, Katznelson L, Walsh M, Guccione A, Cannan J, Heller H, Basgoz N, Klibanski A 1996 Loss of lean body and muscle mass correlates with androgen levels in hypogonadal men with acquired immunodeficiency syndrome and wasting. Journal of Clinical Endocrinology and Metabolism 81:4051-4058 Grinspoon S, Mulligan K 2003 Weight loss and wasting in patients infected with human immunodeficiency virus. Clinical Infectious Diseases 36:S69-S78

Grunfeld C, Pang M, Doerrler W, Shigenaga JK, Jensen P, Feingold KR 1992 Lipids, lipoproteins, triglyceride clearance, and cytokines in human immunodeficiency virus infection and the acquired immunodeficiency syndrome. Journal of Clinical Endocrinology and Metabolism 74:1045-1052

Hadigan C, Corcoran C, Piecuch S, Rodri guez W, Grinspoon S 2000 Hyperandrogenemia in human immunodeficiency virus-infected women with the lipodystrophy syndrome. Journal of Clinical Endocrinology and Metabolism 85:3544-3550

Heijligenberg R, Romijn JA, Westerterp KR, Jonkers CF, Prins JM, Sauerwein HP 1997 Total energy expenditure in human immunodeficiency virus-infected men and healthy controls. Metabolism: Clinical and Experimental 46:1324-1326

Hernandez HF, Gascuena RR, Escribano SP, Velazquez, Martin MT, Lombera RF, Rubio GR, Pulido OF, Ramon, Costa Perez-Herrero J, Saenz DLC 2001 Diastolic dysfunction in human immunodeficiency virus infection. Revista Espanola de Cardiologia 54:1183-1189 Herst JA, Shepherd FA, Liu P, Butany JW, Houle S, Burkes R, Paul K 1991 Prospective assessment of cardiac function in patients with Kaposi's sarcoma and the acquired immune deficiency syndrome. Clinical \& Investigative Medicine 14:21-27

Johnson JE, Anders GT, Blanton HM, Hawkes CE, Bush BA, McAllister CK, Matthews JI 1990 Exercise dysfunction in patients seropositive for the human immunodeficiency virus. American Review of Respiratory Disease 141:618-622

Johnson JE, Slife DM, Anders GT, Bailey SR, Blanton HM, McAllister CK, Latham RD 1991 Cardiac dysfunction in patients seropositive for the human immunodeficiency virus. Western Journal of Medicine 155:373-379 Jones SP, Doran DA, Leatt PB, Maher B, Pirmohamed M 2001 Short-term exercise training improves body composition and hyperlipidaemia in HIV-positive individuals with lipodystrophy . AIDS 15:2049-2051

Keyes C, Rodgers P, Wolbert J, Marte C, Kelly J, Ribble D 1989 Effect of cardiovascular conditioning in HIV infection. International Conference on AIDS 5:

Keyser RE, Peralta L, Cade WT, Miller S, Anixt J 2000 Functional aerobic impairment in adolescents seropositive for HIV: a quasiexperimental analysis. Archives of Physical Medicine and Rehabilitation 81:1479-1484

King MA, Neal DE, St John R, Tsai J, Diaz PT 1997 Bronchial dilatation in patients with HIV infection: CT assessment and correlation with pulmonary function tests and findings at bronchoalveolar lavage. American Journal of Roentgenology. 168:1535- 1540

Kotler DP, Tierney AR, Wang J, Pierson RN 1989 Magnitude of body-cell-mass depletion and timing of death from wasting in AIDS. American Journal of Clinical Nutrition 444-447

Kotler DP, Wang J, Pierson RN 1998 Body composition studies in patients with the acquired immunodeficiency syndrome. American Journal of Clinical Nutrition 42: 1255-1265

Kvale PA, Rosen MJ, Hopewell PC, Markowitz N, Hansen N, Reichman LB,
Wallace JM, Glassroth J, Fulkerson W, Meiselman L 1993 A decline in the pulmonary diffusing capacity does not indicate opportunistic lung disease in asymptomatic persons infected with the human immunodeficiency virus. Pulmonary Complications of HIV Infection Study Group. American Review of Respiratory Disease 148:390-395

LaPerriere A, Fletcher MA, Antoni MH, Klimas NG, Ironson G, Schneiderman, N. 1991 Aerobic exercise training in an AIDS risk group. International Journal of Sports Medicine 12 Suppl 1:S53-S57

LaPerriere A, Ironson $\mathrm{G}$, Antoni $\mathrm{MH}$, Schneiderman N, Klimas N, Fletcher, MA. 1994 Exercise and psychoneuroimmunology. Medicine and Science in Sports and Exercise 26:182-190

Laurence J, Mayer L 1984 Immunoregulatory lymphokines of $\mathrm{T}$ hybridomas from AIDS patietns: constitutive and inducible suppressor factors. Science 225:66-69

Lawless D, Jackson CG, Greenleaf JE 1995 Exercise and human immunodeficiency virus (HIV-1) infection. Sports Medicine 19:235-239

Lipshultz SE, Orav EJ, Sanders SP, Hale AR, McIntosh K, Colan SD 1992 Cardiac structure and function in children with human immunodeficiency virus infection treated with zidovudine. New England Journal of Medicine 327:1260-1265

MacArthur RD, Levine SD, Birk TJ 1993 Supervised exercise training improves cardiopulmonary fitness in HIV-infected persons. Medicine and Science in Sports and Exercise 25:684-688

McCabe RN, Baron J, Griffin R, Omogbehin M, Snashall PD, Seed WA 1997 Effects of smoking and clinical status on lung function in human immunodeficiency virus (HIV)seropositive subjects. Respiratory Medicine 91:221-229

McDermott AY, Shevitz A, Knox T, Roubenoff R, Kehayias J, Gorbach S 2001 Effect of highly active antiretroviral therapy on fat, lean, and bone mass in HIV-seropositive men and women. American Journal of Clinical Nutrition 74:679-686

Mehta NJ, Khan IA, Mehta RN, Gowda RM 2002 Acute coronary syndrome in patients with human immunodeficiency virus disease. Angiology 53:545-549

Meng Q, Lima JA, Lai H, Vlahov D, Celentano DD, Strathdee S, Nelson, KE, Tong W, Lai S 2002 Use of HIV protease inhibitors is associated with left ventricular morphologic changes and diastolic dysfunction. JAIDS Journal of Acquired Immune Deficiency Syndromes 30:306-310

Milei J, Grana D, Fernandez AG, Matturri L 1998 Cardiac involvement in acquired immunodeficiency syndrome--a review to push action. The Committee for the Study of Cardiac Involvement in AIDS. Clinical Cardiology 21:465-472

Mondy K, Tebas P 2003 Emerging bone problems in patients infected with human immunodeficiency virus. Clinical Infectious Diseases 36:S101-S105 
Nieman RB, Fleming J, Coker RJ, Harris JR, Mitchell DM 1993 Reduced carbon monoxide transfer factor (TLCO) in human immunodeficiency virus type I (HIV-I) infection as a predictor for faster progression to AIDS. Thorax 48:481-485

Pacht ER, Diaz P, Clanton T, Hart J, Gadek JE 1997 Alveolar fluid glutathione decreases in asymptomatic HIV-seropositive subjects over time. Chest 112:785-788

Pantaleo G, Graziosi C, Fauci AS 1993 The immunopathogenesis of human immunodeficiency virus infection. New England Journal of Medicine 328:327-335

Pedersen BK, Rohde T, Ostrowski K 1998 Recovery of the immune system after exercise. Acta Physiologica Scandinavica 162:325-332 Pothoff G, Wassermann K, Ostmann H 1994 Impairment of exercise capacity in various groups of HIV-infected patients. Respiration 61:80-85

Power R, Tate HL, McGill SM, Taylor C 2003 A qualitative study of the psychosocial implications of lipodystrophy syndrome on HIV positive individuals. Sexually Transmitted Infections 79:137-141

Raboud JM, Haley L, Montaner JS, Murphy C, Januszewska M, Schechter MT 1995 Quantification of the variation due to laboratory and physiologic sources in CD4 lymphocyte counts of clinically stable HIV-infected individuals. Journal of Acquired Immune Deficiency Syndromes 10 Suppl 2:S67-S73

Reussner D, Kraus MF, Lamwersiek H 1992 The effects of a physical activity program on HIV-positive men and women. International Conference on AIDS 8:126

Rigsby LW, Dishman RK, Jackson AW, Maclean GS, Raven PB 1992 Effects of exercise training on men seropositive for the human immunodeficiency virus-1. Medicine and Science in Sports and Exercise 24:6-12

Roge BT, Calbet JA, Moller K, Ullum H, Hendel HW, Gerstoft J, Pedersen BK 2002 Skeletal muscle mitochondrial function and exercise capacity in HIV-infected patients with lipodystrophy and elevated p-lactate levels. AIDS 16:973-982

Rosenberg ZF, Fauci AS 1990 Immunopathogenic mechanisms of HIV infection. Immunology Today 11:176-180

Roubenoff R 2000 Exercise and HIV Infection. Nutrition in Clinical Care 3: 230-236

Roubenoff R, Abad LW, Lundgren N 2001 Effect of acquired immune deficiency syndrome wasting on the protein metabolic response to acute exercise. Metabolism: Clinical and Experimental 50:288-292

Roubenoff R, Grinspoon S, Skolnik PR, Tchetgen E, Abad L, Spiegelman, D, Knox T, Gorbach S 2002a Role of cytokines and testosterone in regulating lean body mass and resting energy expenditure in HIV-infected men. American Journal of Physiology Endocrinology and Metabolism 283:E138-E145

Roubenoff R, Schmitz H, Bairos L, Layne J, Potts E, Cloutier GJ, Denry F 2002b Reduction of abdominal obesity in lipodystrophy associated with human immunodeficiency virus infection by means of diet and exercise: case report and proof of principle. Clinical Infectious Diseases 34:390-393

Roubenhoff R, Skolnik PR, Shevitz A, Snydman L, Wang A, Melanson S, Gorbach S 1999 Effect of a single bout of acute exercise on plasma human immunodeficiency virus RNA levels. Journal of applied Physiology 86:1197-1201

Roubenoff R, Weiss L, McDermott A, Heflin T, Cloutier GJ, Wood M, Gorbach S 1999 A pilot study of exercise training to reduce trunk fat in adults with HIV-associated fat redistribution. AIDS 13:1373-1375

Roubenoff R, Wilson IB 2001 Effect of resistance training on self-reported physical functioning in HIV infection. Medicine and Science in Sports and Exercise 33:1811-1817

Rutherford GW, Lifson AR, Hessol NA, Darrow WW, O'Malley PM, Buchbinder SP 1990 Course of HIV-1 infection in a cohort of homosexual and bisexual men: an 11 year follow-up study. British Medical Journal 301:1183-1188

Samaan SA, Foster A, Raizada V, Schade DS, Koster F, Crawford MH 1995 Myocardial atrophy in acquired immunodeficiency syndrome-associated wasting. American Heart Journal 130:823-827

Sattler F 2003 Body habitus changes related to lipodystrophy. Clinical Infectious Diseases 36:S84-S90

Sattler FR, Jaque SV, Schroeder ET, Olson C, Dube MP, Martinez C, Briggs W, Horton R, Azen S 1999 Effects of pharmacological doses of nandrolone decanoate and progressive resistance training in immunodeficient patients infected with human immunodeficiency virus. Journal of Clinical Endocrinology and Metabolism 84:1268-1276

Sattler FR, Schroeder ET, Dube MP, Jaque SV, Martinez C, Blanche PJ, Azen S, Krauss RM 2002 Metabolic effects of nandrolone decanoate and resistance training in men with HIV. American Journal of Physiology Endocrinology and Metabolism 283:E1214E1222

Schlenzig C, Jager H, Rieder H, Hammel G, Popescu M 1989 Supervised physical exercise leads to psychological and immunological improvement in pre-AIDS patients. International Conference on AIDS 5:337

Sheik RA, Yasmeen S, Munn R, Ruebner BH, Ellis WG 1999 AIDS-related myopathy. Medical Electron Microscopy 32:79 -86

Shevitz AH, Knox TA 2001a Nutrition in the era of highly active antiretroviral therapy. Clinical Infectious Diseases 32:1769 -1775

Shevitz AH, Knox TA 2001b Nutrition in the era of highly active antiretroviral therapy. Clinical Infectious Diseases 32:1769-1775

Shisana O 2003 http://allafrica.com/publishers. html?passed_name $=$ South $\% 20$ African $\% 20$ Press $\% 20$ Association\&passed_location= Johannesburg

Simpson DM, Bender AN 1988 Human immunodeficiency virus-associated myopathy: analysis of 11 patients. Annals of Neurology 24:79-84
Smith BA, Neidig J, Nickel J, Frid D, Para M, Fass R 1996 Effects of aerobic and resistive exercise on symptoms, immune status, and viral load in HIV+ men and women. International Conference on AIDS 11:23

Smith BA, Neidig J, Nickel J, Frid D, Para M, Fass R 1998 Effects of aerobic and resistive exercise training on body composition, immune markers, and viral load in HIV+ adults with CD4+ counts $200-499 / \mathrm{mm}^{3}$. International Conference on AIDS 12:23 Smith BA, Neidig JL, Nickel JT, Mitchell GL, Para MF, Fass RJ 2001 Aerobic exercise: effects on parameters related to fatigue, dyspnea, weight and body composition in HIV-infected adults. AIDS 15:693-701

Steinhart CR 2001 HIV-associated wasting in the era of HAART: a practice-based approach to diagnosis and treatment. AIDS Reader 11:557-559

Steinherz LJ, Brochstein JA, Robins J 1986 Cardiac involvement in congenital acquired immunodeficiency syndrome. American Journal of Diseases of Children 140:1241-1244

Strawford A, Barbieri T, Van Loan M, Parks E, Catlin D, Barton N, Neese, R, Christiansen M, King J, Hellerstein MK 1999 Resistance exercise and supraphysiologic androgen therapy in eugonadal men with HIV-related weight loss: a randomized controlled trial. Journal of the American Medical Association 281:1282-1290 Stringer WW 2000 Mechanisms of exercise limitation in HIV+ individuals. Medicine and Science in Sports and Exercise 32:S412-S421 Stringer WW, Berezovskaya M, O'Brien WA, Beck CK, Casaburi R 1998 The effect of exercise training on aerobic fitness, immune indices, and quality of life in HIV+ patients. Medicine and Science in Sports and Exercise 30:11-16

Talle MA, Rao PE, Westerberg E, Allegar N, Makowski M, Mittler RS, Goldstein G 1983 Patterns of antigenic expression on human monocytes as defined by monoclonal antibodies. Cell Immunology 78:83-99

Tebas P, Powderly WG, Claxton S, Marin D, Tantisiriwat W, Teitelbaum SL Yarasheski KE 2000 Accelerated bone mineral loss in HIV infected patients receiving potent antiretroviral therapy. AIDS 14:F63-F67

Terry L, Sprinz E, Ribeiro JP 1999 Moderate and high intensity exercise training in HIV-1 seropositive individuals: a randomized trial. International Journal of Sports Medicine 20:142-146

Thoni GJ, Fedou C, Brun JF, Fabre J, Renard E, Reynes J, Varray A, Mercier J 2002 Reduction of fat accumulation and lipid disorders by individualized light aerobic training in human immunodeficiency virus infected patients with lipodystrophy and/or dyslipidemia. Diabetes Metababolism 28:397-404

Ullum H, Palmo J, Halkjaer-Kristensen J, Diamant M, Klokker M, Kruuse A, Laperrier AR, Pedersen BK 1994 The effect of acute exercise on lymphocyte subsets, natural killer cells, proliferative responses, and cytokines in HIV-seropositive persons. Journal of Acquired Immune Deficiency Syndromes 7:1122-1133 Wrzolek MA, Sher JH, Kozlowski PB, Rao C 1990 Skeletal muscle pathology in AIDS: an autopsy study. Muscle and Nerve 13:508-515 